\title{
Sustainability of Vocabulary Teaching After Explicit Instruction in Kindergarten Children
}

\section{İsmail Zeki Dikici and Naciye Kunt}

Department of English Language Teaching, Faculty of Education, Eastern Mediterranean University Famagusta, via, Mersin 10, Turkey

Correspondence: ismailzeki2001@yahoo.co.uk,+90 2522111286

\begin{abstract}
This study investigates five-year-old learners' vocabulary retention through case studies, on a one week, one month, three months, and five months basis. It concerns the vocabulary learning of kindergarten children learning English as a second language (L2). This study attempts to seek answers to the questions of to what extent the presentation of the three different sets of words more effective than the other two is, both on recall and recognition and whether the recall and recognition levels showed differences in the three sets of words in course of time. In the literature, some studies have favoured semantic mapping in which new words are presented and organized in terms of associated lexical meanings. Some other studies have disfavoured semantic mapping. This study has administered three different sets of vocabulary: semantically related, cognates and semantically unrelated words. This study indicated that all participants were more successful with semantically related words on word recall and with cognates on word recognition. The results of this study do not support those which claim that making semantic associations may cause interference and hinder vocabulary learning. This study further suggests that semantically related words should be taught thematically to facilitate vocabulary teaching, particularly on word recall.
\end{abstract}

Key words: Cognates; Kindergarten children, Recall; Recognition; Vocabulary retention 


\section{Introduction}

This study looks to a group of kindergarten children's vocabulary retention through three sets of words: semantically related, cognates and semantically unrelated. It concerns the vocabulary learning of kindergarten children learning English as a second language (L2).

Vocabulary has attracted scholars' interest in the field of English language teaching and is at the heart of so many recent studies. [1], has laid emphasis on text comprehension with regard to one's native language or in a foreign language that is crucial to be able to understand most of the vocabulary in a text. Similarly, [2], contended that in the organization of syllabuses and other variables, such as the evaluation of learner performance, vocabulary holds one of the most important aspects of language teaching. Furthermore, [3], maintained that grammatical competence does not mean a great proficiency in a language and that the bulk of learning a new language consists largely the learning of new vocabulary. The related literature review indicated a body of contradicting studies; [4], there is no consensus on several issues regarding vocabulary studies, which seem to have evolved as a result of methodological biases. One such bias concerns whether new vocabulary should be taught in semantically related sets or semantically unrelated sets.

The review of the related literature yielded revealed that a body of scholars $[5,6,7,8,9,10,11,12]$ favoured the presentation of new words in semantic sets or clusters, as learners could broaden their vocabulary only when they related new lexical items to their background knowledge. Whereas, the negative impact of semantic sets has been discussed by such scholars as $[13,14,15,16,4]$, suggested that if the words falling into the same semantic field are learnt at the same time, learning got hindered due to the confusion stemming from semantic overlap.

\section{Claims that favour the presentation of vocabulary in semantic sets}

The argument in this field is mainly based on the linguistic theory of Semantic Field developed by Trier in the 1930's. [17], contended that words resemble mosaics with clear-cut boundaries where gaps or overlaps can cause change in the whole lexical system. According to Porzig, there is a pivotal word around which the meaning of other words is defined i.e., ride a horse, a camel, a bike, a donkey, an ox etc. [18] contended that semantic fields show not only that a certain group of words 
are related in meaning but also how they are related, through the relationships of hypernymy, hyponymy and coordination and that vocabulary learning can be best performed through interrelating cobwebs of lexical elements, where the meaning of each words is represented by the meanings of the related words in the semantic networks. [19] contended that each word meaning in our minds is a unit that connects to semantically related ones and that the word-web or the semantic network is formed by the associations of each unit. Therefore, the storage and retrieval of words in one's mind strongly depended upon those that are semantically related. Furthermore, according to [20], once children began to acquire lexical items, they are more likely to learn lexical items of the same domain simultaneously. [21] contended that semantic mapping forms associative networks for words, which then helps bring into consciousness the relationships between the words in a text and one's pre-existing knowledge. Furthermore, [22] claimed that semantic mapping is a useful technique to teach vocabulary that enables the teacher to assess the students' prior schema availability on the selected topic. [11], claimed that vocabulary should be presented in semantic sets, provided it was presented in an appropriate context so that learners could benefit not only from deeper levels of mental processing but also from shallow levels.

Such claims have had strong effects in favour of semantic mapping on the English language teaching materials and as a result of this, new vocabulary items have been presented in thematic and semantic clusters, which can be defined as clusters of semantically related words, e.g., eye, nose, ear, mouth, chin [23]. Some recent examples of such course materials are the New Cutting Edge Elementary- [24], New Headway Beginner - [25], and New Total English Elementary- [26], In such materials, the vocabulary is usually presented as a set of words around a superordinate term, which is believed to aid vocabulary building and lexical associations. [27],contended that grouping lexical items on the basis of semantic connections can ease and facilitate student's vocabulary learning and that it also enabled them to make semantic connections through word families.

\section{Claims that disfavour the presentation of vocabulary in semantic sets and Interference Theory and Distinctiveness Hypothesis}

A body of recent studies in the literature showed some negative effects of learning lexical items in semantic sets. In one of the early studies, [28], aimed to test 
the degrees of retroactive inhibition resulting from the interpolation of materials and for that purpose, they focussed on the learning of interpolated lists of synonyms, antonyms, unrelated adjectives and nonsense syllables. Of all these word lists, the lowest performance was with synonyms, as the learning interfered with synonyms. The results of their study were in favour of a theory of retroactive inhibition, which led to the formation of Interference Theory. A substantial body of literature can be found on Interference Theory and its effect on learning, cognition, and memory $[29,30,31,32]$, In fact, "interference theory" assumes that when words, which are too "similar" or share too many common elements are learnt simultaneously, then these words may impede with each other, thus impairing any memory retention of them. The extent of interference is likely to be higher with the degree of which the interfering material became more similar to the material already learnt; semantically related L2 vocabulary is believed to cause undesirable impediments in L2 or learning, which is influenced by subsequently acquired knowledge [14],

[33], found that learning words on the basis of semantic categories hindered learning and that when learners were instructed words that had a common superordinate concept, these words were learnt more slowly than those words which did not share a common superordinate term. In line with this study, [14], used Japanese words, matched them with some artificial words and concluded that presenting students with semantically related words usually interfered with, and hindered learning. Learning of semantically grouped words took more time and that their retrieval required more effort on the learners[14]. [34], investigated the role of interference from English to French and French to English, and the findings showed that the unrelated words were more easily learnt, though interference was observed with semantically related words. [16], investigated the "deleterious effect" of semantically similar words on vocabulary learning and reported a semantic interference effect during the process of encoding of information into one's memory and the retrieval of information from L1 to L2. [4], investigated the effect of teaching vocabulary in semantic sets at a primary school in Turkey. Participants in this study had little or no prior exposure to English. There were two sets of words: semantically related and unrelated words. This study lasted for three weeks. During the experimental phase, the participants were shown some flashcards. The learning activities were designed in the form of repetition drills and lexical matching activities. On the post-tests, the participants were asked to match the pictures and words. The 
findings of this study supported the negative effect of teaching words in semantic sets. The findings of his study revealed that there was a statistically significant difference in favour of the unrelated vocabulary grouping. [35], in her study in Poland with lower primary children found that their final statistical scores were significantly better with unrelated words.

The reason why this study was conducted with young learners lay in the number of studies conducted on young learners so far. The number of studies regarding kindergarten children's vocabulary retention is scarce, particularly in Turkey and all over the world [36], over the past six years, less researched contexts include elementary or primary schools (14 studies); adult education (13 studies); preschools (three studies) and language programs and institutions as a whole (six studies). These statistics indicated that teaching English to young learners is a growing field of study, but that the least studied part of young learners was in preschool education.

This interest in introducing foreign language instruction has increasingly included young learners (YLs) in Turkey as well as elsewhere in the world. Foreign language teaching in Turkey has often been characterised by reform movements in education introduced by the Turkish Ministry of Education-Milli Eğitim Bakanlığı (MEB). To fully understand these reforms and curricula changes, so many factors can be taken into consideration: the diffusion of English, the teacher education system and the demands of the English market system. Turkish learners in state schools start learning a foreign language, which is usually English, in their fourth to eighth years of primary education; whereas, most kindergartens or private schools provide their students with English from the very beginning of their education.

\section{Characteristics of kindergarten children and the preferred approach towards learning and teaching}

There are many variables in children's vocabulary growth, teaching cognitively or semantically related words and real-life connections between words and their use that are recommended by a number of scholars [37], emphasized that semantic sorting helped students improve their vocabulary knowledge by emphasizing how words and concepts relate or do not relate to one another. Systematic review helped students solidify the learning that occurred during the past weeks [38]. Review 
activities were not meant to be a reteaching of the words learned, but rather extensions of the information students the learned about a word [37].

The process of children learning an L2 includes three dynamic processes: cognitive development, a continuing L1 development and the relatively new process of L2 acquisition [35]. Therefore, this process may hinder L2 acquisition in young learners. Some principles regarding young learners' learning have been briefly summarized, although in children's learning there are different ways of learning and it is believed that children learn mainly through play. Children's perspectives on play and learning should be taken into account by advocating a play-based pedagogy approach or by integrating more learning elements into a play-oriented curriculum [36] and social interaction [38]. Some techniques, such as the use of visual or verbal aids or realias, as well as verbal explanation in their mother tongue that can be used in vocabulary teaching to young learners [35]. Vocabulary teaching to children is believed to be enhanced through the use of visuals (e.g. pictures, video), pointing and labelling of words and choral repetition of words. Teachers mainly use strategies that enhance the recognition and memorisation of words [39]. In order to perform this, teachers can prepare pictures, photographs or flashcards that contain both words and pictures or draw pictures on the board to illustrate the actual words taught or the sounds associated with the target words. [39], in their study of kindergarten children learning English in Hong Kong, found that teachers adopted a limited variety of instructional practices in teaching vocabulary. The most commonly used practices included the use of visuals (e.g. pictures, video).

Conceptual development across early school years has an important influence on the vocabulary growth in children's foreign language learning. First of all, the types of words that children learn change with age. At the age of five, they only learn very concrete vocabulary related to objects they can handle or see. When they are older, they find it possible to cope with words and topics that are more abstract and remote from their immediate surroundings. [40], further argued that teaching vocabulary to children had to include the recycling of words. Vocabulary knowledge has to be constantly expanded and deepened by frequent repetition, presenting words in different contexts and linking words in networks of meaning.

Children's learning of a second or foreign language involves three dynamic processes: cognitive development, a continuing first language development and the relatively new process of second language acquisition [41]. These processes are 
apparent in the lexical development of children when they are still building up their L1 vocabulary.

Learning words is a cyclical process, which involved an exposure to new words and initial learning, followed by repeatedly meeting those words each time, extending knowledge of what the words meant and how they are used in the foreign language: For children to develop conceptual learning, they may need to become exposed to the words used in so many different contexts; the facility for detecting and identifying words and other perceptual objects is improved by repeated encounters with the same words or objects [42]. All through childhood, words are used only with a partial understanding of the full meaning system that underlay them and that as children got older, they became more aware of certain aspects of language, such as the semantic connections between words [40]. Furthermore, learning words requires repeated exposure to these new words with an extension of their meaning and the way they are used in the foreign language in different contexts: For children to develop conceptual learning, they may need to be exposed to words that are used in different contexts; the detection and retrieval of word meaning is improved through repeated encounters with the same words [42]. The closely related issue here is which type of retention of words will be superior to the other one, namely recall or recognition of words. [43], suggested that recognition memory performance can be considered closely linked to recall. This would enable subjects to explicitly evaluate their memory so that they can either retrieve items at recall level or simply recognize items at recognition level.

Teachers should be aware of the fact that any learner has his/her own learning style and so do young learners. Teachers could select topics and vocabulary around these topics to accordingly evoke their interests. Another issue at stake is with the materials for young learners; teaching English to young learners is a rapidly growing field of ELT in Turkey, and sometimes it may be hard to find suitable materials for young learners of English. It is the English teacher's task to select appropriate materials for teaching vocabulary to young learners. Materials should be in line with young learners' levels and teachers should select such materials that can enable young learners to make semantic associations, so that young learners can get involved in deeper levels of mental processing. There is no formal curriculum to teach English to kindergarten children in the preschool education in Turkey. Hence some kindergartens, particularly those private ones, teach English in the form of extra- 
curricular activities or some voluntary activities performed by those in and out of school. Just like in this study, the researchers performed some language activities after obtaining permission from the participants' parents and the kindergarten. The overall aim of this study is to provide evidence based on kindergarten children to try out effective ways of vocabulary teaching. It investigated kindergarten children's vocabulary retention through three sets of words: semantically related, cognates and semantically unrelated.

This is a case study based on conversation analytic principles tracing the language development of participants.

This study is based on the following research questions:

1. To what extent is the presentation of the three different sets of words more effective than the other two, both on recall and recognition?"

2. Do recall and recognition levels show differences in the three sets of words in course of time?

\section{Methods}

\section{Participants}

This study involved 8 Turkish children, aged five, with no prior experience of L2 learning. The participants in this study had little or no prior exposure to English. Interviews with parents revealed that the participants mostly communicated in their L1 at home and that they did not speak any other languages, except Turkish.

The sample for this study was 5-year-old kindergarten children at the kindergarten of Muğla University. 8 children out of 20 were selected as non-random, through conveniently selected sampling. Before the research was launched the researcher went to the kindergarten to consult with the headmaster of the school regarding the feasibility of the research. The headmaster first asked the parents to find out how they reacted to the research and all of them reacted positively. Then, the researcher wrote to the dean of the faculty where he worked and also to the rector for a permission; Necessary permissions were granted from children's parents and audio recordings were made every week during class hours. 


\section{Data Collection}

Fifteen nouns in three sets of vocabulary were selected as target items, as nouns are more likely to evoke images and considered easier for younger learners to learn and are thus more meaningful than verbs or adjectives [44]. Currently, there are no research studies to indicate the exact number of new words that specific age groups can learn at once. However, our experience suggests that learning two or three words at a time is appropriate for most pre-schoolers, whereas kindergarteners may handle three to five new words at a time [45].

A special emphasis was laid on the selection of developmentally appropriate practices. The activities were designed in such a way that the children would be physically and mentally active. The target words were presented in three groups of five lexical items. The following criteria were taken into consideration in the selection of the target items:

The children in this study were all familiar with the selected target items; they had already somehow seen the objects or the pictures of the objects, in their daily lives. The study focussed on children developing an understanding of concepts about themselves, others and the world around them through observation and interactions with people and real objects.

Within the first group, the words presented were: cow, goat, milk, grass and cheese. These words were presented in a context so that they would make sense in terms of semantic mapping. The second group of words consisted of cognates: television, train, radio, yoghurt, and bicycle. These words were selected as they were similar to their L1 in terms of pronunciation. The third group of words consisted of unrelated words: ball, flower, fish, sun and table. These words were recognisable to children from their everyday experience but this group of words was specially selected, and special emphasis was laid on the fact that there would be no cognates in this group.

In each set of vocabulary, there were only five words. The reason for that was that the research into memory development has consistently shown that younger children recall less than older children, both in standard tests of memory, such as list learning, and in more natural tasks, such as the recall of a personally experienced event. Young children's recall is typically accurate, but very incomplete when compared to that of older children [46]. 
At the outset, a discrimination test was administered through the Peabody Picture Vocabulary Test [47]. The words that were planned to be used in the study were presented to the children, and therefore it was ascertained that they were not already familiar with their vocabulary in English. The children were presented with plates of four pictures and asked to show the word produced by the tester. The test contained 180 items grouped into 15 sets of 12 items; four of the items had black and white illustrations while the rest were in different colours. The tester asked the participating children to identify a selected item on each picture plate that had corresponded to the stimuli.

The Peabody Picture Vocabulary Test (PPVT) was a great help to the researchers for two reasons. First, the researchers were able to identify which words to use in their study; the words already known by the children were excluded and second, the test also indicated the children's level of recognition. The researchers also developed Flashcards. These flashcards were drawn and some of them downloaded from various websites or compiled from books. Data was collected on a one week, one month, three months, and five months basis to investigate the participants' vocabulary retention levels.

The researchers who presented the words did so in an order. The first set of words (cow, goat, milk, grass and cheese) was presented in a context in Turkish. The presentation was in the following way: Bu keçi [tr: this is a goat], Bu inek [tr: this is a cow], Onlar ne yerler? -çimen. [tr: what do they eat? -grass]. Onlar bize ne verir? -süt. [tr: what do they give us? -milk]. Sütten ne yaparız? [what do we make from milk?] Peynir [tr: cheese].

The second set of words was cognates, which were: television, train, radio, yoghurt, and bicycle. These words were selected as they were similar to their L1 in terms of their pronunciation. The researchers at this stage first asked them what they were in Turkish and showed them the flashcards and got them to repeat the words.

The third set of words, which were unrelated words were: ball, flower, fish, sun and table. The children were familiar with them from their everyday experience. The researchers used repetition and choral response in their presentation with flashcards for words that were unrelated semantically; they were not presented in a context, but in a random manner. 
During presentation, such techniques were used. Miming was used to mime/imitate such objects as "cow, goat, train" by making the noises they produced. The children were then asked to guess what it was and then to repeat that word, first in Turkish. They were then shown the relevant flashcards, the words of which were repeated by the children, and in the meantime, the flashcards of these objects were put on the board.

The next stage was the "hands-on" stage where the children were presented a set of five cards (i.e., first set of words, second set of words or third set of words) representing the copies of the pictures presented on the flashcards. The cards were not coloured and the children were supposed to colour them in; so, the children were asked to one by one colour in the words they had learnt.

At the "testing stage", each child was tested for recognition/recall individually in a quiet room. They were shown picture flashcards to prompt their recall of an English equivalent by pointing to the picture and asking bu ne? [tr: what is this?] where the student replied: İnek [tr: a cow] The words were instructed only one at a time and audiotaped and evaluated four times during one semester course (a week, month, and three months/five months) after the vocabulary sets had been introduced. The procedure had been adopted from [41].

\section{Data Analysis}

The data in this research study were analysed using the Overall Data Analysis Procedures [49]:

1. The transcribing of the scripts was the first step, which involved the researchers' listening and re-listening of the audio records of the study conducted with the participants to create text scripts. All the audio data was transcribed first and checked for the second time. The transcription of the scripts paved the way for the first steps, namely, lexically oriented analysis.

2. The next step was coding, which had to do with the omission of inaudible and unrelated data (i.e., children crying or wanting to go to the toilet etc.,) and where new labels were attached to data segments. The codes were then defined operationally in terms of their meaning.

3. Following the coding/labelling stage, there was the clustering step. The related codes or tags were categorised under general headlines, which involved 
generating categories. For providing a coherent analysis and easing the referral process, data retrieval was arranged.

4. Consequently, the results of the interrelated data collection tools were accumulated to see the whole result of a research question. In line with the findings, each research question was analysed in-depth.

5. Finally, it was written up utilising strategies, such as exemplifying, describing, constructing, verifying, quoting and displaying.

\section{Results}

There were four data collection sessions in this study. Data was collected on a one week, one month, three months, and five months basis. This was a case study with eight participants, and the scores obtained through conversation analysis were transformed into charts and graphs. The overall results indicated that the highest scores on word recall level belonged to semantic mapping, whereas on word recognition level they belonged to cognates. The lowest scores both on recall and recognition levels belonged to the set of unrelated words. The average percentage of vocabulary recall and recognition levels of participants are given in Table 1 and Figure 1.

Table 1 . The participants' vocabulary recall and recognition mean percentages.

One week

One month

Three months

Five months

Recall Recognition Recall Recognition Recall Recognition Recall Recognition

\begin{tabular}{lcccccccc}
$\begin{array}{l}\text { Related } \\
\text { words }\end{array}$ & 70 & 82.5 & 62.5 & 82.5 & 60 & 72.5 & 45 & 65 \\
Cognates & 70 & 95 & 54 & 90 & 50 & 88 & 42.5 & 85 \\
Unrelated & 65 & 82.5 & 60 & 72.5 & 57 & 60 & 40 & 50 \\
\hline
\end{tabular}


In the first data collection session, the recall levels for the three sets of words were $70 \%, 70 \%$ and $65 \%$ respectively, whereas the scores for recognition level were $82.5 \%, 95 \%$ and $82.5 \%$, respectively. In the second data collection session, the recall levels for the three sets of words were $62.5 \%, 54 \%$ and $60 \%$, respectively, whereas the scores for recognition level were $82.5 \%, 90 \%$ and $72.5 \%$, respectively. In the third data collection session, the recall levels for the three sets of words were $60 \%, 50 \%$ and $57 \%$, respectively, whereas the scores for recognition level were $72.5 \%, 88 \%$ and $60 \%$, respectively. In the fourth data collection session, the recall levels for the three sets of words were $45 \%, 42.5 \%$ and $40 \%$, respectively, whereas the scores for recognition level were $65 \%, 85 \%$ and $50 \%$, respectively.

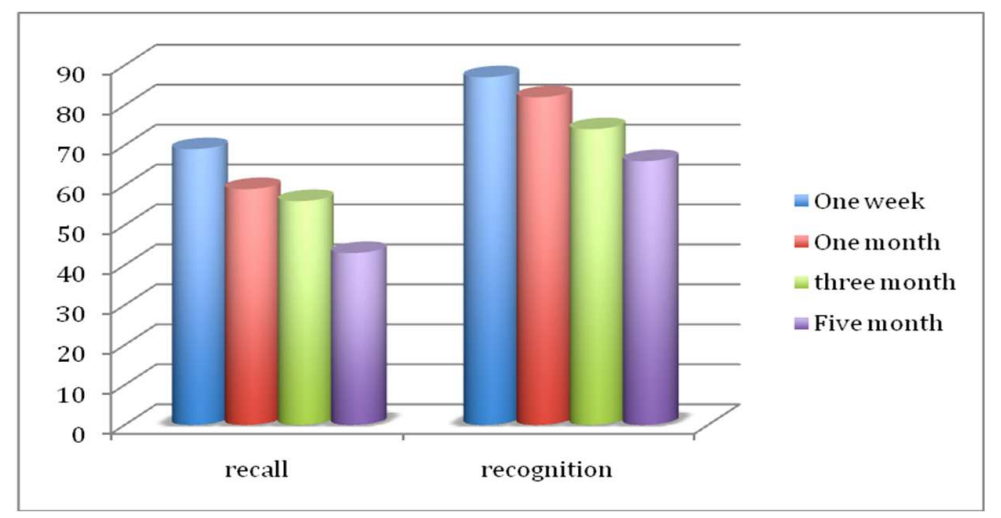

Figure 1. The participants' vocabulary recall and recognition levels on a one week, one month, three months, and five months basis.

As can be seen from Table 1 and Figure 1, recall and retention levels of the participants tended to decrease. Overall, the average recognition scores are higher than the recall ones. The findings of this study indicated that vocabulary teaching and learning can be enhanced through such techniques as above and that embedding words in meaningful contexts can be done through semantic mapping. The reason why there were four different vocabulary sessions was to investigate whether the study would show significant differences in terms of its time span.

\section{Discussion}

The above findings also support Trier's semantic field theory that vocabulary in a language is semantically related and builds up a complete lexical system. In this study, the semantically related set of words: "cow, goat, milk, cheese and grass" have 
developed in the participants' lexical system as they were instructed in context but not in isolation and since vocabulary has been studied as an integrated system. The words in this lexical set have become mosaics attached to each other and have become meaningful around a pivotal word i.e., around cow or goat, so that the other words: milk, cheese and grass could become meaningful. The finding that the semantically related set of words have attained higher scores on the word recall levels with all participants is in line with the "semantic field theory" as well as the "network or cobweb theory" where each word meaning in our minds is a unit that connects to semantically related ones that the word-web or the semantic network is formed by the associations of each unit and that the storage and retrieval of words in one's mind strongly depends upon those that are semantically related.

Semantic mapping can be helpful in teaching English to young learners on word recall level, though on word recognition level, cognates worked better. On the basis of the data obtained, it can be assumed that the words which evoked associations with their L1 are best remembered. Especially if they consisted of the sounds that exist in their L1 phonological system. Therefore, it can be assumed that they are subsumed to the same category in the mental lexicon [35].

Research findings indicated that as the time span increased, both recall and retention levels tend to drop. [48], indicated that this effect is probably due to the participants lack of exposure to or receiving of follow-up practice with the target words. These results imply that a one-time lesson alone is insufficient for a long-term retention of newly learned words. Regarding the retention of learned words, the learners' mean scores in the present study dropped significantly on the delayed vocabulary test. They forgot some of the learned words with time [50].

\section{Conclusion and Recommendations}

Based on the above findings it can be claimed that semantic mapping can be more effective with five-year-olds, in both short and long-term recall and cognates can be more effective in short and long-term recognition, since all the participants performed in the same way. It can be claimed that vocabulary teaching to five-year-olds can be done more effectively, accordingly.

Some variations were observed in their recall and recognition in all the three sets of words. In the long-term retention, there seemed to be more variation between 
recall and recognition. These variations sustained over time. Individual variation showed that in implicit instruction, children with low short-term memory seemed to gain more breadth of vocabulary in the short run, but also to forget more in the long run [51]. Furthermore, the vocabulary sets were not selected randomly. Special attention was paid to the fact that they were related to the children's experience so far, that they were related to their everyday life and evoked their interests. The activities were in line with the intellectual level of the children, namely there were no difficult constructions related to grammar. All through childhood, words are used with only a partial understanding of the full meaning system that underlay them and that it was as they got older, they became more aware of certain aspects of language, such as the semantic connections between words. Therefore, teaching vocabulary in chunks can be useful in making semantic associations as it may evoke the young learner's interests[40].

This study, like any study may have limitations as it involved a limited number of participants and a very limited number of words was presented. The participants were five-year-olds, who may have not have developed their conceptual learning; therefore, they may have need to be exposed to words in different contexts and the meaning of the vocabulary needed to be extended. Similarly, repeated encounters with the same vocabulary may enhance the retrieval of word meaning.

In line with the findings of this study and the literature review, some implications can be suggested for EFL and ESL classrooms. As it has been shown in this study, vocabulary should be taught in a meaningful context and vocabulary teaching can be arranged around a pivotal word and under related topics or headings, particularly with young learners who to some extent learn English by heart and who do not develop any inhibitions; in such cases, semantic mapping can be a useful technique. Young learners, especially five-year-old learners are dynamic and cheerful and need to be engaged in practice activities, therefore, the teacher can administer a combination of Total Physical Response (TPR) and Total Emotional Response (TER) activities in teaching English to young learners [35]. Furthermore, different methods and approaches i.e., TPR or TER can be tried out to check their efficiency with different vocabulary sets on kindergarten children. 


\section{References}

1 Laufer, B. The lexical plight in second language reading. In J Coady \& T Huckin (Eds.), Second Language Vocabulary Acquisition: A Rationale for Pedagogy. Cambridge: CUP. 1997.

2 Candlin, C. N. Preface. In R Carter \& M McCarthy (Eds.), Vocabulary and language teaching. New York: Longman. 1988.

$3 \mathrm{Xu}, \mathrm{F}$. ; Li, T. Semantic frame and EVT for Chinese EFL learners. Journal of Language Teaching and Research, 2011, 2 (3), 649-654.

4 Erten, I. H. ; Tekin, M. Effects on vocabulary acquisition of presenting new words in semantic sets versus semantically-unrelated sets. System, 2008, 36 (3), 407 422.

5 Vogt, D. Semantic mapping as a vocabulary teaching technique to improve recall of word meaning. MEd. Dissertation. Montana: Eastern Montana College. 1983.

6 Carr, E. ; Wixson, K. K. Guidelines for evaluating vocabulary instruction. Journal of Reading, 1986, 29, 588-595.

7 Haycraft, J. An introduction to English language teaching. Kuala Lampur: Longman. 1993.

8 Stoller, F. ; Grabe, W. Implications for L2 vocabulary acquisition and instruction from L1 vocabulary research. In T Huckin, M Haynes \& J Coady (eds.), Second language reading and vocabulary learning. New Jersey: Ablex Publishing Corporation. 1993.

9 Aitchison, J. Taming the wilderness: Words in the mental lexicon. In G M Anderman \& M A Rogers (Eds.), Words, words, words: The translator and the language learner. London: Multilingual Matters. 1996.

10 Barcroft, J. Effects of sentence writing in L2 lexical acquisition. Second Language Research, 2004. 20, 303-334.

11 Hashemi, M. R. ; Gowdasiaei, F. An attribute-treatment interaction study: Lexical set versus semantically-unrelated vocabulary instruction. RELC Journal, 2005. 36 (3): $341-361$.

12 Nilforoushan, S. The effect of teaching vocabulary through semantic mapping on EFL learners' awareness of the affective dimensions of deep vocabulary knowledge. English Language Teaching, 2012. 5(10), 164-172. http://dx.doi.org/10.5539/elt.v5n10p164 
13 Laufer, B. A factor of difficulty in vocabulary learning: deceptive transparency. AILA Review, 1989, 6, 10-20.

14 Waring, R. The negative effects of learning words in semantic sets: A replication. System, 1997, 25, 261-274.

15 Nation, I. S. P. Learning vocabulary in lexical sets: dangers and guidelines. TESOL Journal, 2000 . 9, 6-10.

16 Finkbeiner, M. ; Nicol, J. Semantic category effects in second language word learning. Applied Psycholinguistics, 2003. 24, 369-383.

17 Kleparski, G. A. ; Rusinek, A. The tradition of field theory and the study of lexical semantic change, Zeszyt, 2007. 47, 187-205.

18 Lin, C. C. Semantic network for vocabulary teaching. Journal of Taiwan Normal University, 1997. 42, 43-54.

19 Aitchison, J. Words in the mind: An introduction to the mental lexicon. London: Blackwell. Journal of Second Language Teaching and Research, 1994. 1, 89-87.

20 Clark, E. The lexicon in acquisition. Cambridge: Cambridge University Press. 1993.

21 Morgan, M. Welcome to exemplary practices in vocabulary instruction. Retrieved from www.bridgew.edu/Library/CAGS_Projects/MMORGAN. 8 January 2016, 2003.

22 Debate, E. V. Applying current approaches to the teaching of reading. English Teaching Forum, 2006, 44(1).

23 Tinkham, T. The effects of semantic and thematic clustering on the learning of second language vocabulary. Second Language Research, 1997, 13, 138-163.

24 Cunningham, S. ; Moor, P. New cutting edge elementary. London: Longman. 2005.

25 Soars, L. ; Soars, J. New Headway Elementary. Oxford : Oxford University Press. 2002.

26 Foley, M. ; Hall, D. New total English elementary. London: Pearson. 2011.

27 Gairns, R. ; Redman, S. Working with words: A guide to teaching and learning vocabulary. New York: Cambridge University Press. 1986.

$28 \mathrm{McGeoch}$, A. ; McDonald, W. T. Meaningful relation and retroactive inhibition. American Journal of Psychology, 1931. 43, 579-588.

29 McGeoch, J. A. The psychology of human learning. New York: Longman, 1942. 
30 Higa, M. Interference effects of intralist word relationships in verbal learning. Journal of Verbal Learning and Verbal Behavior, 1963, 2, 170-175.

31 Baddeley, A. D. Human memory: Theory and practice. London: Lawrence Erlbaum, 1997.

32 Anderson, M. C. Rethinking interference theory: Executive control and the mechanisms of forgetting. Journal of Memory and Language, 2003, 49, 415445 .

33 Tinkham, T. The effect of semantic clustering on the learning of second language vocabulary. System, 1993, 21, 371-380.

34 Schneider, V. I. Healy, A. F. ; Bourne, L. E. J. What is learned under difficult conditions is hard to forget: Contextual interference effects in foreign vocabulary acquisition, retention, and transfer. Journal of Memory and Language, 2002, 46, 419-440.

35 Szpotowicz, M. Second Language Acquisition in Lower Primary Children. Warsaw: Wydawnictwa Uniwersytetu Warszawskiego, 2008.

$36 \mathrm{Wu}, \mathrm{S}$. What can Chinese and German children tell us about their learning and play in kindergarten?. Journal of Research in Childhood Education, 2015, 29(3), 338-351.

37 Baker, D. L.; Santoro, L.; Ware, S.; Cuéllar D.; Oldham A.; Cuticelli M .; McCoach B. Understanding and implementing the common core vocabulary standards in kindergarten. Teaching Exceptional Children, 2015, 47(5), 264-271.

38 Coyne, M. D. ; McCoach, D. B. ; Kapp, S. Vocabulary intervention for kindergarten students: Comparing extended instruction to embedded instruction and incidental exposure. Learning Disabilities Quarterly, 2007, 30, 74 - 88.

$39 \mathrm{Lau}$, C. ; Rao, N. English vocabulary instruction in six early childhood classrooms in Hong Kong. Early Child Development \& Care, 2013, 183(10), 1363-1380.

40 Cameron, L. Teaching languages to young learners. Cambridge: Cambridge University Press, 2001.

41 Szpotowicz, M. Factors influencing young learners' vocabulary acquisition. In M.

Nikolov (Ed.), Early Learning of Modern Foreign Languages Processes and

Outcomes. Bristol: Multilingual Matters, 2009, 195-211.

42 Tulving, E. ; Schacter, D. L. Priming and human memory systems. Science, 1990, 247, 301-396. 
43 Haist, F.; Shimamura, A.P.; Squire, L.R. On the relationship between recall andrecognition memory. Journal of Experimental Psychology: Learning,Memory, and Cognition, 1992, 18, 691-702.

44 Ellis, N. ; Beaton, A. Factors affecting the learning of foreign language vocabulary: Imagery keyword mediators and phonological short-term memory. The Quarterly Journal of Experimental Psychology Section A, 1993, 46, 533-58.

45 Christ,T.; Wang, X. C. Supporting preschoolers' vocabulary learning: using a decision-making model to select appropriate words and methods, Young Children, 2012, 67 (2), 74-80.

46 Davidson, L. E. ; G. V. Thomas. Effects of drawing on children's item recall. Journal of Experimental Child Psychology. 2001, 78, 155-177.

47 Dunn, L. M. ; Dunn, L. M. Peabody Picture Vocabulary Test-III. Circle Pines, MN: American Guidance Service, 1997.

48 Nagata, N. The effectiveness of computer-assisted interactive glosses. Foreign Language Annals, 1999, 32, 469-479.

49 Collins, A. B. ; Yıldırım, A. Applying content analysis to qualitative data: an example from a case study on school-based instructional supervision. Eğitim ve Bilim, 2000, 25(117), 64-72.

50 Ko, H.M. Glossing and second language vocabulary learning. TESOL Quarterly, 2012, 46, 56-79.

51 Carmen M. P.; Damhuis, E. S.; Femke, S.; Ludo, V. Effects of individualized word retrieval in kindergarten vocabulary intervention. School Effectiveness and School Improvement, 2016, 27(3), 441-454. 